\title{
Pomace management reduces spread of vine mealybugs
}

by Rhonda J. Smith and Lucia G. Varela

A fter vine mealybug was first identified in North Coast wine-grape vineyards in 2002, growers and wineries needed answers to reduce the movement of this pest between vineyards. We investigated the potential for vine mealybugs to survive in one type of winery waste (or pomace) that is often spread over the vineyard floor during the harvest period.

The pomace we investigated contains unfermented berry skins, seeds and cluster stems. This fresh material is produced by pressing hand-harvested whole clusters or mechanically harvested berries; the juice is then fermented. Alternatively, clusters are processed by a destemmer-crusher, after which skins and seeds are fermented with the juice, producing sediment also known as pomace. Because insects do not survive the fermentation process, we focused on the survival of vine mealybug in fresh pomace collected from the winery press after whole clusters were pressed, as well as in piles of fresh pomace placed on the vineyard property.

\section{Mealybug survival after whole-cluster} press. Two trials were conducted in wineries located in Sonoma County to determine if vine mealybug survived whole-cluster pressing. In the first trial, a 6-ton load of inregime ranging from 0.2 to 1.8 bars of pressure. Before pressing, we found an average of 47 live vine mealybugs per cluster. After the press was completed, there were an average of 0.04 live vine mealybugs per cluster $(0.085 \%$ survival). In the second trial, single infested clusters were placed inside mesh bags and added to a 12-ton load of 'Chardonnay' grapes that underwent a found an average of over 4,800 vine mealyfested 'Grenache' grapes underwent a press similar press regime. Before pressing, we

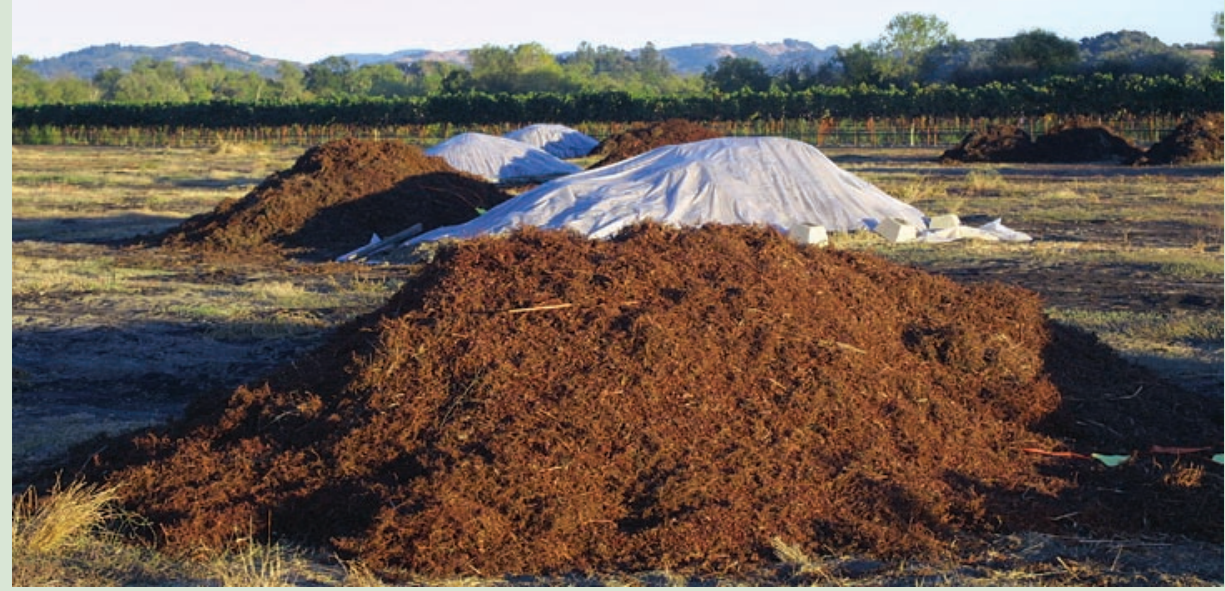

Pomace piles were covered with clear plastic or remained uncovered to evaluate vine mealybug survival. bug crawlers (the small immature stage) per cluster. Afterward, this dropped to an average of 192 crawlers per cluster (4.0\% survival).

These trials showed that vine mealybugs can survive whole-cluster pressing. As a result, fresh pomace can be a source of vine mealybug contamination for wineries or growers who traditionally spread this harvest residue directly in the vineyard or who stockpile unmanaged piles of it near the vineyard.

\section{Controlling mealybugs in pomace.} Another experiment evaluated vine mealybug mortality in static pomace piles that were either uncovered or covered with clear plastic. Infested cluster stems were placed inside mesh bags that were then inserted 1-foot (0.3 meter) and 3 -feet ( 0.9 meter) deep into pomace piles that were 4 feet (1.2 meters) tall and 15 feet $(4.5$ meters) across, approximately the size of piles created by dump trucks commonly used by wineries. Initially, the
TABLE 1. Reduction in vine mealybug on cluster stems after 1 and 4 weeks in two depths, in covered and uncovered pomace piles

\begin{tabular}{|c|c|c|c|c|}
\hline \multirow[b]{2}{*}{ Treatment } & \multirow[b]{2}{*}{ Pile composition } & \multirow{2}{*}{$\begin{array}{l}\text { Infested stem } \\
\text { position in pile }\end{array}$} & \multicolumn{2}{|c|}{ Reduction in vine mealybug } \\
\hline & & & Week 1 & Week 4 \\
\hline & & & $\ldots \ldots$ & $\cdots \ldots$ \\
\hline \multirow[t]{4}{*}{ Uncovered piles } & \multirow[t]{2}{*}{ Mostly stems } & Top & 67.6 & 89.4 \\
\hline & & Bottom & 60.7 & 87.5 \\
\hline & \multirow{2}{*}{$\begin{array}{c}\text { Mostly skins and seeds; } \\
\text { few stems }\end{array}$} & Top & 99.9 & $>99.9$ \\
\hline & & Bottom & 99.9 & 100 \\
\hline \multirow[t]{4}{*}{ Covered piles } & \multirow[t]{2}{*}{ Mostly stems } & Top & $>99.9$ & 100 \\
\hline & & Bottom & 100 & 100 \\
\hline & \multirow{2}{*}{$\begin{array}{c}\text { Mostly skins and seeds; } \\
\text { few stems }\end{array}$} & Top & 100 & 100 \\
\hline & & Bottom & $>99.9$ & $>99.9$ \\
\hline
\end{tabular}

clusters had an average of 1,211 live vine mealybugs per stem.

Results showed that vine mealybug mortality was higher when pomace piles were covered for 1 to 4 weeks with clear plastic than when piles were left uncovered (table 1). When uncovered, more vine mealybugs survived in piles consisting of mostly stems discarded from the destemming process than in the denser, moister piles composed primarily of berry skins and seeds from the whole-cluster press. Uncovered piles composed primarily of stems had greater survival of vine mealybug over time because these piles did not generate high enough temperatures to kill vine mealybugs.

In contrast, when pomace piles were covered, vine mealybugs were reduced by nearly $100 \%$ in both "stemmy" and nonstemmy piles. In addition, when covered there was no difference in mortality at different depths in either type of pile. Fresh pomace piles generate heat as organic material degrades. Temperature loggers recorded significantly lower fluctuation at higher temperatures of $120^{\circ} \mathrm{F}$ to $130^{\circ} \mathrm{F}\left(50^{\circ} \mathrm{C}\right.$ to $55^{\circ} \mathrm{C}$ ) in pomace piles with fewer stems and more moisture, than at temperatures of $68^{\circ} \mathrm{F}$ to $130^{\circ} \mathrm{F}\left(20^{\circ} \mathrm{C}\right.$ to $\left.55^{\circ} \mathrm{C}\right)$ in piles with a greater mass of cluster stems, which are slower to break down (data not shown).

Recommendations. To reduce the risk of contaminating vineyards with mealybugs, growers should avoid spreading pomace in vineyards unless it has been 
covered with plastic for at least 1 week. Optimally, pomace piles should be located away from vine rows and securely covered as soon as feasible, so heat that is generated remains inside the pile. To help increase temperatures inside stemmy piles and decrease vine mealybug survival, cluster stems collected from a winery's destemmer should be mixed with dense material, such as pomace from either whole-cluster or mechanically harvested press loads. Frontend loaders, which are commonly used in many wineries, may be used to mix pomace piles to some degree.

We did not evaluate the survival of vine mealybug in composted pomace. At facilities required to obtain a Compostable Materials Handling Facility Permit from the California Integrated Waste Management Board, regulations require that the windrow composting process under aerobic conditions maintain a temperature of $131^{\circ} \mathrm{F}$ $\left(55^{\circ} \mathrm{C}\right)$ or higher for 15 days or longer to reduce pathogens. During that period, the windrow must be turned a minimum of five times. Given these rigorous requirements, this process is likely to result in similar or increased mortality of vine mealybugs compared to static, covered pomace piles.

Sanitation practices are recommended to avoid spreading any species of mealybug. Many wineries, regardless of size, find it challenging to cover pomace with clear plastic as it is generated. During the harvest period, pomace may be produced daily at a rate of approximately a ton of pomace for every 3 to 6 tons of grapes, so the lack of space to store and manage this material away from grapevines is a critical problem. Bins and dump trucks that are used to move pomace during the production process may potentially contaminate subsequent loads of fresh grapes with mealybugs. Containers used to haul grapes and pomace should be cleaned with a high-pressure sprayer before they are moved offsite.

R.J. Smith is Viticulture Farm Advisor, UC Cooperative Extension (UCCE), Sonoma County; and L.G. Varela is Integrated Pest Management (IPM) Advisor, UC Statewide IPM Program and UCCE Sonoma County. This study was funded in part by the USDA Exotic/Invasive Pests and Diseases Research Program.
East, noting that this parasitoid is probably a complex of more than one species (Triapitsyn et al. 2007) and other "strains" may be better suited for California.

Gill's mealybug. Very little is known about parasitoids of $F$. gilli, as this species was only described in 2003. From collections of F. gilli in El Dorado County vineyards, as well as San Joaquin Valley almonds, it appears that Acerophagus sp., Chrysoplatycerus sp. and Anagyrus pseudococci will attack F. gilli. High levels of parasitism have been recorded by Acerophagus sp. nr. meritorius (Gahan) or A. sp. nr. mundus (Gahan) (the species cannot be determined because of indecisive species descriptions and poor type specimens [Daane et al. 2008]). The Acerophagus sp. was most likely present in California as a parasitoid of the closely related striped mealybug, Ferrisia virgata. Currently, research is investigating parasitism levels of F. gilli in Sierra Foothill vineyards.

Pink hibiscus mealybug. In India, the pink hibiscus mealybug is a major pest of grapes, reducing yields 50\% to $100 \%$. That it is not a pest in California vineyards may be the direct result of a successful biological control program that has limited its spread in the state. After the mealybug was found in the Caribbean in 1994, a cooperative classical biological control project was established for that region, and later extended to California when the pink hibiscus mealybug was found south of the Coachella Valley table-grape region. The parasitoids Anagyrus kamali Moursi, Gyranusoidea indica Shafee, Alam \& Agarwal and Allotropa sp. nr. mecrida (Walker) were released and, over a 5-year period, mealybug density progressively declined to noneconomic levels (Roltsch et al. 2006). Currently, pink hibiscus mealybug populations are maintained at low levels by these natural enemies, and the pest populations have been contained in the very southern portion of the state - currently out of vineyard growing areas.

\section{Manipulating natural enemies}

Insecticides. Vineyard mealybugs are often controlled with insecticides. Prior to the 1990s, most insecticides were not compatible with biological controls. For example, early grape mealybug controls included fumigation with potassium cyanide (Essig 1914), and later materials included DDT and organophosphates (e.g., parathion) (Stafford and Kido 1955). Eventually it became evident that the insecticidal materials disrupted the relatively good control provided by parasitoids. Flaherty et al. (1982) stated that "extensive use of DDT and other synthetic insecticides used to control grape leafhopper disrupted natural control of grape mealybug." Currently, there are many effective materials, such as systemic neonicotinoids, insect growth regulators and tetronic acids that inhibit lipid biosynthesis, which can be used with reduced impact on natural enemy populations. Use of these more narrowspectrum materials may have a less disruptive effect on biological controls.

Ant controls. Ants can exacerbate mealybug pest problems by disrupting natural enemy activity in vineyards (Daane et al. 2007). Unfortunately, insecticide controls for ants are often more disruptive than materials applied for the mealybugs. For that reason, researchers have developed protein and sugar baits for ant control in vineyards, which can be effective alternative practices (see page 177).

Augmentation. There are few reports of successful augmentation when natural enemies are reared in an insectary and released into the targeted habitat - for mealybug control in vineyards, in part because this has not been adequately studied.

In fact, one of the first commercial insectaries in North America was developed in 1916 to rear the mealybug destroyer for the citrus mealybug (Smith and Armitage 1920). Today, this beetle is commonly released in vineyards, but release rates, timing and expected outcomes have not been scientifically evaluated. Until those studies are conducted, understanding the biology of the mealybug destroyer may help improve release effectiveness. Beetles are sold as adults and when released into the vineyard they typically begin searching for mealybug ovisacs, where they will deposit eggs. If no ovisacs are found, many of the beetles may fly away; therefore, releases should be timed to coincide with the presence of ovisacs (or females depositing crawlers in the case of the longtailed mealybug). 